\title{
Genotype by environment interactions in relation to growth traits in slow growing chickens
}

\author{
Aya Lydie N'Dri ${ }^{\mathrm{a}}$, Nadine SELLIER ${ }^{\mathrm{a}}$, Michèle TIXIER-BOICHARD ${ }^{\mathrm{b}}$, \\ Catherine BEAUMONT ${ }^{\mathrm{a}}$, Sandrine MIGNON-GRASTEAU ${ }^{\mathrm{a} *}$ \\ ${ }^{a}$ UR83 Recherches avicoles, INRA, 37380 Nouzilly, France \\ b UMR1236 Génétique et diversité animales, INRA-INA PG, Domaine de Vilvert, \\ 78352 Jouy-en-Josas, France
}

(Received 3 November 2006; accepted 19 April 2007)

\begin{abstract}
Since feed conversion ratio (FCR) is higher in slow-growing "Label Rouge" chickens than in broiler chickens, it is important to work on its improvement in this breed. However, this involves rearing animals in cages $(\mathrm{C})$, an environment very different from that used for selection (in floor pens, S) and production (outdoor, E). The aim of this study was to evaluate the importance of genotype by environment $(\mathrm{G} \times \mathrm{E})$ interactions between $\mathrm{S}, \mathrm{C}$, and $\mathrm{E}$ environments, to find the best way to select for FCR, using 2002 related animals. Growth curve parameters were estimated and body composition measured. Individual feed conversion ratios (FCR) were recorded between 8 and 10 weeks in $\mathrm{C}$. The presence of $\mathrm{G} \times \mathrm{E}$ interactions was assessed by the genetic correlations between the same trait recorded in different environments. Moderate but significant $\mathrm{G} \times \mathrm{E}$ interactions were detected for carcass traits, a significant one was observed between $\mathrm{E}$ and $\mathrm{S}$ or $\mathrm{C}$ for growth curve parameters but none between $\mathrm{C}$ and $\mathrm{S}$. If $\mathrm{G} \times \mathrm{E}$ interactions are set aside, i.e. selecting on traits recorded in $\mathrm{C}$, abdominal fatness is the best indirect selection criterion for FCR but if they are taken in account then leg yield or growth curve parameters in $\mathrm{S}$ and growth curve parameters in $\mathrm{E}$ are better.
\end{abstract}

interaction / genetic parameters / feed efficiency / chicken / selection

\section{INTRODUCTION}

Feed represents $70 \%$ of the total cost of broiler production. The feed conversion ratio (FCR) may be improved by direct selection [10,24], especially in Label Rouge chickens, in which the feed conversion ratio is much higher than in broilers [8], ranging from 3.00 to 3.47 between 6 and 8 wk [17, 25, 28, 30].

* Corresponding author: grasteau@tours.inra.fr 
In Label Rouge production, animals are reared in extensive conditions. Regulations impose for example a low density, a low-energy diet, free-range rearing from 6 weeks to slaughter, and a minimum slaughter age of $81 \mathrm{~d}$. Consequently, specific slow-growing meat-type genotypes have to be used in Label Rouge production.

Measurement of FCR is very constraining. In broilers, feed efficiency may also be improved as a correlated response to selection for younger age at market weight. However, increasing body weight at a given age has several consequences such as increased fatness and maintenance cost at a given age [16,23]. Since regulations impose a minimum slaughter age of $81 \mathrm{~d}$ in "Label Rouge" chickens, selecting for increased growth rate is not permitted. Indirect selection on correlated traits should therefore provide alternative selection strategies. The criteria to be considered for indirect selection may be abdominal fatness [16] as well as growth curve parameters, since lines selected on the shape of the growth curve exhibit different feed conversion ratios [26]. Furthermore, selection strategies to improve the feed conversion ratio have been investigated primarily for fast-growing broilers, and their application to slowgrowing label-type chickens may not be straightforward. Due to the differences in the environment needed to measure FCR (i.e. cage) which may lead to significant $\mathrm{G} \times \mathrm{E}$ interactions, selecting directly on FCR may be difficult. In a previous study [21] we estimated genetic correlations between growth curve parameters, carcass composition and feed efficiency in slow growing meat-type "Label Rouge" chickens reared in cages. The results showed the feasibility of indirect selection on feed conversion ratio using growth curve parameters and abdominal fat yield. However, in this study possible $\mathrm{G} \times \mathrm{E}$ interactions were not taken into account. Since the production environment is a free-range system, $\mathrm{G} \times \mathrm{E}$ interactions are probably present.

The purpose of this study was therefore to evaluate the presence and importance of $\mathrm{G} \times \mathrm{E}$ interactions in a slow growing commercial line of chickens used for French "Label Rouge" type production, in order to take them into account in the choice of the best indirect selection criterion for improving FCR. The environments that were considered were therefore individual cages, to record FCR individually, a traditional selection environment used by the breeder i.e. in floor pens but indoors and production environment, with access to openair. Genotype by environment interactions were estimated by considering any given trait recorded in different environments as different traits $[2,11]$. The presence of $\mathrm{G} \times \mathrm{E}$ interaction was then detected if the estimated genetic correlation between these traits was significantly less than unity. Direct selection responses on FCR were then compared to indirect selection responses using 
growth curve parameters or body composition recorded in the three different environments as selection criteria.

\section{MATERIALS AND METHODS}

\subsection{Animals and rearing systems}

A total of 2002 chickens (999 males and 1003 females) with known genealogy were taken from four successive hatches for this experiment. They originated from a pure commercial slow growing meat-type line dedicated to the production of French "Label Rouge" chickens. All animals were obtained from the same 50 sires and 148 dams. At hatching, full sibs were allocated to three different environments. In the first environment (C), animals were floor reared until 6 weeks of age and transferred into individual cages until slaughter. In the second environment (S), animals were reared indoors in floor pens from hatching to slaughter (birds with the same sire per pen), corresponding to usual selection conditions. In the last environment (E), animals were reared under production conditions, i.e. indoors in floor pens until 6 weeks, and with access to open air afterwards. The total number of animals reared for the experiment was 1061 in C (in two hatches, with 542 birds hatched in week 47 of 2002 and 519 hatched in week 02 of 2003), 396 in S conditions (hatched in week 15 of 2003), and 545 in E conditions (hatched in week 12 of 2003).

Since the pedigree was available over nine generations, the pedigree file included 13384 animals. Inbreeding was estimated at $2 \%$ on average, with a maximum at $8 \%$.

Chicks were sexed, wing-banded and vaccinated against Marek disease at hatching. They were given ad libitum access to water and food. A starter diet (2831 Kcal ME $\cdot \mathrm{kg}^{-1}, 20.9 \%$ protein, Tab. I) was given between 0 and $28 \mathrm{~d}$, followed by a grower diet (2938 Kcal ME $\cdot \mathrm{kg}^{-1}, 18.0 \%$ proteins) between $29 \mathrm{~d}$ and $61 \mathrm{~d}$, and by a finisher diet (3020 Kcal ME $\cdot \mathrm{kg}^{-1}, 16.0 \%$ proteins) from $62 \mathrm{~d}$ to slaughter.

\subsection{Recorded traits}

\subsubsection{Weight}

In all environments, chickens were individually weighed at 1 week (BW1), 4 weeks (BW4), 6 weeks (BW6), 8 weeks (BW8), 10 weeks (BW10), and at slaughter (BWS). Slaughter occurred at different ages in the three environments, in order to slaughter chickens at the same weight (2000 g). Animals 
Table I. Composition of starter, growing and finishing diets.

\begin{tabular}{lccc}
\hline & Starter diet & Growing diet & Finishing diet \\
\hline Age (d) & $0-28$ & $29-61$ & 62 -slaughter \\
AME (kcal· $\left.\cdot \mathrm{kg}^{-1} \mathrm{DM}\right)$ & 2831 & 2938 & 3020 \\
Crude proteins (\%) & 21.0 & 18.0 & 16.0 \\
Wheat (\%) & 20.0 & - & 30.0 \\
Corn (\%) & 43.1 & 72.5 & 50.0 \\
Soybean meal (\%) & 31.4 & 21.0 & 10.9 \\
Oil (\%) & 0.50 & - & 0.25 \\
Corn gluten (\%) & 1.0 & 2.8 & 5.2 \\
Calcium carbonate (\%) & 1.02 & 0.70 & 0.80 \\
Dicalcium phosphate (\%) & 1.90 & 1.94 & 1.74 \\
Sodium chloride (\%) & 0.40 & 0.40 & 0.30 \\
Minerals and vitamins Premix (\%) & 0.50 & 0.50 & 0.50 \\
DL-Methionine (\%) & 0.14 & 0.10 & 0.09 \\
Lysine (\%) & - & 0.10 & 0.24 \\
\hline
\end{tabular}

were therefore killed at $74 \mathrm{~d}$ and $75 \mathrm{~d}$ in the first and second hatching in the $\mathrm{C}$ environment, at $77 \mathrm{~d}$ in the $\mathrm{S}$ environment, and at $84 \mathrm{~d}$ in the E environment.

\subsubsection{Feed intake traits}

Animals were transferred to cages at 6 weeks, but FCR was not calculated between 6 and 8 weeks, which was considered as a period of habituation to the cage. The feed conversion ratio (FCR) was therefore individually determined only between 8 and 10 weeks. Residual feed consumption (RES) was calculated for the same period according to a multiple regression equation established on our data, including metabolic body weight and weight gain between 8 and 10 weeks $[3,4,29]$. In S, FCR was also calculated per floor pen, each pen corresponding to the progeny of one sire.

\subsubsection{Carcass traits}

Birds from the three environments were slaughtered in the same slaughterhouse by the same procedure. After scalding, plucking, and gut removal, carcasses were stored at $4{ }^{\circ} \mathrm{C}$ for $20 \mathrm{~h}$ on average until dissected. Individual carcass weight $(\mathrm{CW})$ was recorded before dissection and right breast muscle 
weight (BRW), right leg weight (thigh and drumstick, LW), and abdominal fat weight (AFW) were recorded for each animal. Breast muscle yield (BRY), leg yield (LY), and abdominal fat yield (AFY) were expressed as percentages of carcass weight.

\subsubsection{Growth curve parameters}

Growth curve parameters were estimated using the Gompertz equation, according to Laird et al. [13]:

$$
\mathrm{BW}_{\mathrm{t}}=\mathrm{BW}_{0} \mathrm{e}^{\left(\frac{\mathrm{L}}{\mathrm{K}}(1-\mathrm{e}(-\mathrm{Kt}))\right)}
$$

where $\mathrm{BW}_{\mathrm{t}}$ is the body weight at age $\mathrm{t}, \mathrm{BW}_{0}$ the estimated weight at hatching, $\mathrm{L}$ the initial specific growth rate $\left(\right.$ i.e., $\left(1 / \mathrm{BW}_{\mathrm{t}}\right) \times\left(\mathrm{dBW}_{\mathrm{t}} / \mathrm{dt}\right)$ when $\left.\mathrm{t} \rightarrow 0\right)$, and $\mathrm{K}$ the maturation rate or the exponential factor of decay of the specific growth rate.

We calculated the coordinates of age at inflexion (TI), for which the growth rate is at maximum, as follows:

$$
\mathrm{TI}=\left(\frac{1}{\mathrm{~K}}\right) \ln \left|\frac{\mathrm{L}}{\mathrm{K}}\right| .
$$

Growth curve parameters were estimated by non-linear regression with the NLIN procedure of SAS ${ }^{\circledR}$ [27], taking into account all available weights from birth to slaughter. In the $\mathrm{C}$ environment, transfer to cages led to much slower growth rates between 6 and 8 weeks (habituation), followed by high growth rates between 8 and 10 weeks (compensatory growth). In that environment, BW8 was therefore not included in the estimation of growth curve parameters in order not to affect our estimates. Body weights at each age were weighted by the ratio of the phenotypic variance of slaughter weight to the phenotypic variance of $\mathrm{BW}_{\mathrm{t}}$, as suggested by Mignon-Grasteau et al. [19], in order to take into account the increase in variance of body weight with age.

\subsection{Exploratory analysis}

Basic statistics on feed consumption, feed efficiency and residual feed consumption were calculated by the PROC MEANS procedure of SAS ${ }^{\circledR}$ [27]. Analysis of variance was performed using the PROC GLM of SAS ${ }^{\circledR}$ [27] to test the effects to be included in the model (sex and hatch). For FCR and RES, 
we also tested the effect of position of the bird in the battery (floor 1 to 3 , middle or edge of the battery).

For traits recorded in the three environments, the significance of differences between environments was tested by GLM using the following model:

$$
y_{i j k l}=\mu+e_{i}+h_{j}\left(e_{i}\right)+s_{k}+e_{i j k l}
$$

where $y_{i j k l}$ is the performance of animal $1, e_{i}$ the effect of rearing environment ( $i$ = cage, selection or production), $h_{j}\left(e_{i}\right)$ the effect of hatch $j$ within environment $\mathrm{i}, \mathrm{s}_{\mathrm{k}}$ the effect of sex $\mathrm{k}$, and $\mathrm{e}_{\mathrm{ijk} k}$ the residual of the lth animal.

As FCR residuals showed a skewed distribution, a Box-Cox transformation [5] was applied before genetic analysis, as follows:

$$
\mathrm{FCR}_{\mathrm{t}}=\frac{\mathrm{FCR}^{\mathrm{t}}-1}{\mathrm{t} \times \mathrm{FCR}_{\mathrm{g}}^{(\mathrm{t}-1)}}
$$

where $\mathrm{FCR}_{\mathrm{t}}$ is the transformed value of $\mathrm{FCR}, \mathrm{FCR}_{\mathrm{g}}$ the geometric mean of the FCR, and $t$ the parameter of the transformation (0.4). Parameter $t$ of the transformation was determined on the basis of skewness and kurtosis of $\mathrm{FCR}_{\mathrm{t}}$ residuals by iterative GLM analyses. The range of parameters t tested was -5 to +5 .

\subsection{Genetic analysis}

Genetic parameters of recorded traits were estimated with REML (REstricted Maximum Likelihood) using VCE 4 [22] according to the following model:

$$
\mathbf{y}=\mathbf{X} \boldsymbol{\beta}+\mathbf{Z u}+\mathbf{e}
$$

where $\mathbf{y}$ is the vector of performances $(\mathrm{N}=2002), \boldsymbol{\beta}$ the vector of fixed effect of sex (male or female) and hatch $(\mathrm{N}=4)$, $\mathbf{u}$ the vector of direct additive genetic effects $(\mathrm{N}=13384)$ and $\mathbf{e}$ the vector of residuals. $\mathbf{X}$ and $\mathbf{Z}$ are information matrices related to $\boldsymbol{\beta}$ and $\mathbf{u}$, respectively.

An alternative model was used to evaluate the significance of maternal effects, treated as a common environmental effect:

$$
\mathbf{y}=\mathbf{X} \boldsymbol{\beta}+\mathbf{Z u}+\mathbf{W m}+\mathbf{e}
$$

where $\mathbf{m}$ is the vector of random permanent environmental effect and $\mathbf{W}$ the information matrix related to $\mathrm{m}$.

In order to estimate genetic correlations between the three environments, traits measured in $\mathrm{C}, \mathrm{S}$, and $\mathrm{E}$ were treated as distinct (e.g. for BRY we 
distinguished $\mathrm{BRY}_{\mathrm{C}}, \mathrm{BRY}_{\mathrm{S}}$, and $\mathrm{BRY}_{\mathrm{E}}$, subscripts indicating the environment). Since preliminary analysis showed that the genetic correlations between growth curve parameters in $\mathrm{C}$ and $\mathrm{S}$ environments were all above 0.99 [20], only two traits were distinguished for L, K, and TI, with subscript "SC" for selection and cage traits and "E" for extensive traits.

Since it was not possible to include all traits in a single analysis, we performed several multi-trait analyses. First, a set of analyses was performed to calculate the genetic correlations between traits recorded in different environments, i.e., to evaluate the presence of $\mathrm{G} \times \mathrm{E}$ interactions. The first analysis included $\mathrm{BW} 8_{\mathrm{C}}, \mathrm{BW} 8_{\mathrm{S}}, \mathrm{BW} 8_{\mathrm{E}}, \mathrm{BWS} \mathrm{C}_{\mathrm{C}}, \mathrm{BWS}_{\mathrm{S}}$, and $\mathrm{BWS} \mathrm{S}_{\mathrm{E}}$. For carcass traits, one nine-trait analysis was performed $\left(B R Y_{S}, B Y_{C}, B R Y_{E}, L_{S}, L_{C}, L_{E}\right.$, $\mathrm{AFY}_{\mathrm{S}}, \mathrm{AFY}_{\mathrm{C}}, \mathrm{AFY}_{\mathrm{E}}$ ). The complete six-trait analysis on growth curve parameters did not converge satisfactorily. It was therefore divided into three fourtrait analyses $\left(\mathrm{L}_{\mathrm{SC}}, \mathrm{L}_{\mathrm{E}}, \mathrm{K}_{\mathrm{SC}}\right.$, and $\mathrm{K}_{\mathrm{E}} ; \mathrm{L}_{\mathrm{SC}}, \mathrm{L}_{\mathrm{E}}, \mathrm{TI}_{\mathrm{SC}}$, and $\mathrm{TI}_{\mathrm{E}} ; \mathrm{K}_{\mathrm{SC}}, \mathrm{K}_{\mathrm{E}}, \mathrm{TI}_{\mathrm{SC}}$, and $\mathrm{TI}_{\mathrm{E}}$ ). Then a set of analyses was performed to estimate genetic correlations between FCR or RES and the other traits, in order to evaluate the possibility of indirect selection of these traits. One eight-trait analysis gave correlations between $\mathrm{FCR}_{\mathrm{t}}$, RES and body weights $\left(\mathrm{FCR}_{\mathrm{t}}, \mathrm{RES}, \mathrm{BW} 8_{\mathrm{S}}, \mathrm{BW} 8_{\mathrm{C}}, \mathrm{BW} 8_{\mathrm{E}}\right.$, $\mathrm{BWS}_{\mathrm{S}}, \mathrm{BWS}_{\mathrm{C}}, \mathrm{BWS}_{\mathrm{E}}$ ). Correlations between $\mathrm{FCR}_{\mathrm{t}}$, RES and body composition and growth curve were estimated in four analyses $\left(1: F R_{t}, R E S, L_{S C}\right.$, $\mathrm{K}_{\mathrm{SC}}, \mathrm{TI}_{\mathrm{SC}}, \mathrm{BRY}_{\mathrm{S}}, \mathrm{LY}_{\mathrm{S}}$, and $\mathrm{AFY}_{\mathrm{S}} ; 2: \mathrm{FCR}_{\mathrm{t}}, \mathrm{RES}, \mathrm{L}_{\mathrm{E}}, \mathrm{K}_{\mathrm{E}}, \mathrm{TI}_{\mathrm{E}}, \mathrm{BRY}_{\mathrm{E}}, \mathrm{LY}_{\mathrm{E}}$, and $\mathrm{AFY}_{\mathrm{E}} ; 3$ : $\mathrm{FCR}_{\mathrm{t}}, \mathrm{BRY}_{\mathrm{C}}, \mathrm{AFY}_{\mathrm{C}}, \mathrm{LY}_{\mathrm{C}}, \mathrm{L}_{\mathrm{C}}, \mathrm{K}_{\mathrm{C}}$, and $\mathrm{TI}_{\mathrm{C}}$ from [21]; 4: RES, $\mathrm{BRY}_{\mathrm{C}}, \mathrm{AFY}_{\mathrm{C}}$, and $\mathrm{LY}_{\mathrm{C}}$ from [21]).

Since heritability and genetic correlation estimates are expected to follow a normal distribution, a t test was used to check whether heritability estimates differed from one environment to another, and whether genetic correlations of the same traits recorded in different environments were different from unity, i.e. if $\mathrm{G} \times \mathrm{E}$ was present or not. To try to explain the possible differences in heritability estimates between environments, F tests were used to compare genetic variances and residual variances of the same trait recorded in different environments.

Genetic correlations between $\mathrm{FCR}_{\mathrm{t}}$ or RES and growth curve parameters, body weight or body composition were then used to compare expected responses to direct selection of FCR $\mathrm{t}$ or RES and expected responses to indirect selection of $\mathrm{FCR}_{\mathrm{t}}$ or RES, using growth curve parameters, body weight or body composition as selection criteria. 


\section{RESULTS AND DISCUSSION}

\subsection{Elementary statistics}

Least squares means for each trait in the three environments are given in Table II. The effect of environment was highly significant $(P<0.001)$ for all of the traits except for LY and TI. BW1, BW4, and BW6 were higher in the $\mathrm{S}$ environment than in the $\mathrm{E}$ and $\mathrm{C}$ environments, probably due to the older age of hens when laying eggs for the $\mathrm{S}$ environment. The growth rate in the $\mathrm{C}$ environment was lower between 6 and 8 wk than in the other two environments, followed by compensatory growth in the cage. According to the growth curve, the expected weight for animals at $12 \mathrm{wk}$ in each environment should have been $2475 \mathrm{~g}, 2334 \mathrm{~g}$, and $2176 \mathrm{~g}$ in the C, S, and E environments, respectively.

In agreement with $\mathrm{BW}$ values, $\mathrm{L}$ and $\mathrm{K}$ were lower in $\mathrm{E}$ and higher in $\mathrm{C}$. After inflection, the decrease in the growth rate was slower in $\mathrm{E}$ than in $\mathrm{S}$ and C. BRY and AFY were significantly different in the three environments. BRY was lower and AFY higher in C, which may be related to the impossibility of sustained physical activity in a cage. In contrast, BRY was the highest and AFY the lowest in the E environment, which has been shown to enhance physical activity in broilers [33]. Variability in fatness in the E environment was greater than in the $\mathrm{S}$ or $\mathrm{C}$ environments, in agreement with previous studies $[6,32]$ in which high coefficients of variation occurred for AFW and AFY. FCR was higher in $\mathrm{S}$ than in $\mathrm{C}(3.61 \pm 0.73 v s .3 .15 \pm 0.40)$. Since food consumption was comparable in both environments $(1657 \pm 260 \mathrm{~g}$ in $\mathrm{C} v s$. $1653 \pm 313 \mathrm{~g}$ in $\mathrm{S}, \mathrm{P}>0.05$ ), the difference in FCR should be attributed to the compensatory growth occurring in $\mathrm{C}$ between 8 and $10 \mathrm{wk}$. Feed consumption and FCR were also more variable in the $\mathrm{S}$ environment than in the $\mathrm{E}$ environment ( $+3 \%$ and $+7 \%$ for FC and FCR, respectively). We attributed this to the high feed wastage in S, probably leading to an overestimation of FCR.

\subsection{Genetic parameters}

The contributions of permanent environmental maternal effects were very low for all traits, and did not significantly differ from zero. The results presented below are therefore those obtained with the model (5) without maternal effects. 
Table II. Least squares means for body weight, carcass traits and growth curve parameters (mean $\pm \mathrm{SD}$ ) for each environment.

\begin{tabular}{lccccccc}
\hline & \multicolumn{5}{c}{ Environment } \\
Trait ${ }^{1}$ & \multicolumn{2}{c}{ C } & \multicolumn{2}{c}{ S } & E & General SD \\
& $\mathrm{N}$ & LSMEANS & $\mathrm{N}$ & LSMEANS & $\mathrm{N}$ & LSMEANS & \\
\hline BW1 (g) & 1058 & $81^{\mathrm{a}}$ & 396 & $95^{\mathrm{b}}$ & 545 & $90^{\mathrm{c}}$ & 15 \\
BW6 (g) & 1052 & $884^{\mathrm{a}}$ & 391 & $978^{\mathrm{b}}$ & 535 & $874^{\mathrm{a}}$ & 135 \\
BW8 (g) & 1049 & $1266^{\mathrm{a}}$ & 392 & $1476^{\mathrm{b}}$ & 530 & $1344^{\mathrm{c}}$ & 208 \\
BW10 (g) & 1045 & $1803^{\mathrm{a}}$ & 391 & $1937^{\mathrm{b}}$ & 527 & $1842^{\mathrm{c}}$ & 290 \\
BWS (g) & 1042 & $1973^{\mathrm{a}}$ & 391 & $2138^{\mathrm{b}}$ & 526 & $2181^{\mathrm{c}}$ & 350 \\
CW (g) & 1032 & $1647^{\mathrm{a}}$ & 332 & $1710^{\mathrm{b}}$ & 520 & $1798^{\mathrm{c}}$ & 267 \\
BRW (g) & 1031 & $137^{\mathrm{a}}$ & 332 & $154^{\mathrm{b}}$ & 524 & $168^{\mathrm{c}}$ & 28 \\
LW (g) & 1031 & $252^{\mathrm{a}}$ & 332 & $262^{\mathrm{b}}$ & 524 & $276^{\mathrm{c}}$ & 48 \\
AFW (g) & 1031 & $66^{\mathrm{a}}$ & 332 & $66^{\mathrm{a}}$ & 523 & $43^{\mathrm{b}}$ & 25 \\
CY (\%) & 1031 & $84^{\mathrm{a}}$ & 331 & $80^{\mathrm{b}}$ & 520 & $82^{\mathrm{c}}$ & 4 \\
BRY (\%) & 1031 & $8.3^{\mathrm{a}}$ & 331 & $9.0^{\mathrm{b}}$ & 519 & $9.3^{\mathrm{c}}$ & 0.9 \\
LY $(\%)$ & 1031 & $15.3^{\mathrm{a}}$ & 331 & $15.3^{\mathrm{a}}$ & 518 & $15.3^{\mathrm{a}}$ & 1.0 \\
AFY (\%) & 1031 & $4.0^{\mathrm{a}}$ & 331 & $3.8^{\mathrm{b}}$ & 518 & $2.4^{\mathrm{c}}$ & 1.5 \\
L (d $\left.{ }^{-1}\right)$ & 1031 & $0.136^{\mathrm{a}}$ & 380 & $0.135^{\mathrm{b}}$ & 524 & $0.130^{\mathrm{c}}$ & 0.014 \\
K (d $\left.{ }^{-1}\right)$ & 1031 & $0.031^{\mathrm{a}}$ & 380 & $0.031^{\mathrm{a}}$ & 524 & $0.030^{\mathrm{b}}$ & 0.004 \\
TI (d) & 1031 & $49.7^{\mathrm{a}}$ & 380 & $49.8^{\mathrm{a}}$ & 524 & $49.7^{\mathrm{a}}$ & 7.5 \\
\hline
\end{tabular}

${ }^{1} \mathrm{BW} 1$ = body weight at $1 \mathrm{wk}$; BW4 = body weight at $4 \mathrm{wk}$; BW6 = body weight at $6 \mathrm{wk}$; BW8 = body weight at $8 \mathrm{wk}$; BW10 = body weight at $10 \mathrm{wk}$; BWS = body weight at slaughter; $\mathrm{CW}=$ carcass weight; $\mathrm{CY}=$ carcass yield; $\mathrm{BRW}=$ breast weight; $\mathrm{BRY}=$ breast yield; $\mathrm{LW}=$ leg weight; $\mathrm{LY}=$ leg yield; $\mathrm{AFW}=$ abdominal fat weight; $\mathrm{AFY}=$ abdominal fat yield; $\mathrm{L}=$ initial specific growth rate; $\mathrm{K}=$ maturation rate; $\mathrm{TI}=$ age at inflection; $\mathrm{FC}=$ feed consumption between $8 \mathrm{wk}$ and $10 \mathrm{wk}$; FCR $=$ feed conversion ratio between $8 \mathrm{wk}$ and $10 \mathrm{wk}$; RES $=$ residual feed consumption between $8 \mathrm{wk}$ and $10 \mathrm{wk}$.

${ }^{2}$ Least squares means with different superscripts within a row were significantly different $(P<$ $0.05)$.

\subsubsection{Heritability estimates}

Heritability estimates for the main traits (Tab. III) were moderate to high (from 0.21 to 0.74 ), using the purely additive model. Except for L, K, and BWS, heritability of traits was higher in the $\mathrm{S}$ environment. The high values of heritability of carcass traits were in the upper range of broiler estimates in the literature (0.54 to 0.65 for BRY and 0.50 to 0.80 for AFY $[7,12,14,15,31])$. Heritability of leg yield ranged from 0.23 to 0.60 according to the rearing environment. 
Table III. Heritability estimates $( \pm$ SE) of body weight, growth curve parameters and carcass traits.

\begin{tabular}{|c|c|c|c|}
\hline \multirow{2}{*}{ Traits $^{1}$} & \multicolumn{3}{|c|}{ Heritability estimates in the environment $^{5}$} \\
\hline & $\mathrm{S}^{2}$ & $\mathrm{C}^{2}$ & $E^{2}$ \\
\hline $\mathrm{L}^{3}$ & \multicolumn{2}{|c|}{$0.29 \pm 0.04^{\mathrm{a}}$} & $0.63 \pm 0.06^{\mathrm{b}}$ \\
\hline $\mathrm{K}^{3}$ & \multicolumn{2}{|c|}{$0.27 \pm 0.03^{\mathrm{a}}$} & $0.40 \pm 0.06^{b}$ \\
\hline $\mathrm{TI}^{3}$ & \multicolumn{2}{|c|}{$0.30 \pm 0.03^{\mathrm{a}}$} & $0.25 \pm 0.06^{\mathrm{b}}$ \\
\hline BRY & $0.50 \pm 0.03^{\mathrm{a}}$ & $0.69 \pm 0.05^{\mathrm{b} 4}$ & $0.60 \pm 0.05^{\mathrm{ab}}$ \\
\hline LY & $0.23 \pm 0.03^{\mathrm{a}}$ & $0.60 \pm 0.06^{\mathrm{b} 4}$ & $0.41 \pm 0.04^{\mathrm{c}}$ \\
\hline AFY & $0.66 \pm 0.04^{\mathrm{ab}}$ & $0.74 \pm 0.04^{\mathrm{a} 4}$ & $0.57 \pm 0.04^{b}$ \\
\hline BW8 & $0.54 \pm 0.04^{\mathrm{a}}$ & $0.70 \pm 0.04^{\mathrm{b} 4}$ & $0.56 \pm 0.06^{\mathrm{a}}$ \\
\hline BWS & $0.56 \pm 0.04^{\mathrm{a}}$ & $0.53 \pm 0.04^{\mathrm{a} 4}$ & $0.56 \pm 0.04^{\mathrm{a}}$ \\
\hline
\end{tabular}

${ }^{1} \mathrm{BRY}, \mathrm{LY}$, and $\mathrm{AFY}=$ breast yield, leg yield, and abdominal fat yield, respectively; L, K, and TI $=$ initial specific growth rate, maturation rate, and age at inflection, respectively. BW8, BWS = body weight at $8 \mathrm{wk}$ and body weight at slaughter, respectively.

${ }^{2}$ Subscripts stand for environment in which trait is recorded, i.e. selection (S), cage (C) or extensive (E).

${ }^{3}$ For L, K, and TI, data in selection (S) and cage (C) environments have been grouped together.

${ }^{4}$ From N'Dri et al. (2006) [21].

${ }^{5}$ Heritability estimates for the same traits in different environments with no common superscript were significantly different $(P<0.05)$.

Heritability estimates of growth curve parameters were slightly lower than estimates found in the literature for various broiler genotypes $[1,9,19]$ but estimates were consistent with a previous study on the same line $(0.24$ for $\mathrm{L}$, 0.26 for $\mathrm{K}$, and 0.30 for TI [18]). Heritability estimates of $\mathrm{L}_{\mathrm{C}}$ and $\mathrm{L}_{\mathrm{S}}$ had previously been shown to be similar (0.21 and 0.25 , respectively [21]), and significantly different from heritability of $\mathrm{L}_{\mathrm{E}}(0.50)$. A similar trend was observed for the heritability of $\mathrm{K}\left(0.28,0.28\right.$, and 0.34 for $\mathrm{K}_{\mathrm{C}}, \mathrm{K}_{\mathrm{S}}$, and $\mathrm{K}_{\mathrm{E}}$, respectively). Heritability estimates of TI and BWS were the same in the three environments $(0.25)$.

Three different situations explain the differences in heritability estimates between environments. In the first situation, the genetic variances were higher and the residual variances lower in environment A than in B. Expression of the genetic potential was therefore better in A than in B, with the effects originating from the environment lower, and heritability higher in A than in B. This was the case for BRY and LY, more heritable in S than in C, and for K, more heritable in SC than in E. In the second and third situations, both genetic and residual variances were higher in environment B than in A, suggesting the presence of a scale effect. In the second case, the increase in genetic variance 
Table IV. Estimated genetic correlations of carcass traits and body weight between the three environments $(\mathrm{S}, \mathrm{C}$, and $\mathrm{E})$ taken two by two $( \pm \mathrm{SE})$.

\begin{tabular}{cccc}
\hline \multirow{2}{*}{ Traits $^{1}$} & \multicolumn{3}{c}{ Genetic correlations between environments } \\
& C-S & C-E \pm S-E \\
\hline BRY & $0.90 \pm 0.02$ & $0.84 \pm 0.03$ & $0.84 \pm 0.04$ \\
LY & $0.84 \pm 0.05$ & $0.88 \pm 0.05$ & $0.91 \pm 0.05$ \\
AFY & $0.89 \pm 0.03$ & $0.95 \pm 0.03$ & $0.93 \pm 0.03$ \\
BW8 & $0.76 \pm 0.05$ & $0.98 \pm 0.02$ & $0.74 \pm 0.07$ \\
BWS & $0.82 \pm 0.06$ & $0.97 \pm 0.02$ & $0.76 \pm 0.08$ \\
L & $>0.99^{2}$ & $0.83 \pm 0.06$ to $0.84 \pm 0.06^{3}$ \\
K & $>0.99^{2}$ & $0.76 \pm 0.06$ to $0.82 \pm 0.06^{3}$ \\
TI & $>0.99^{2}$ & $0.68 \pm 0.07$ to $0.75 \pm 0.08^{3}$ \\
\hline
\end{tabular}

${ }^{1}$ BRY, LY, and AFY = breast yield, leg yield and abdominal fat yield, respectively; BW8 and BWS = body weight at $8 \mathrm{wk}$ and body weight at slaughter, respectively; L, K, and TI = initial specific growth rate, maturation rate and age at inflexion, respectively.

${ }^{2}$ From N'Dri et al. (2004) [20].

${ }^{3}$ Genetic correlations between $\mathrm{S}$ or $\mathrm{C}$ and $\mathrm{E}$ environments. Several analyses were performed due to difficulties of convergence.

was proportionately higher than the increase in residual variance, and heritability was higher in A than in B. This was the case for $L\left(h^{2}\left(L_{S}\right)>h^{2}\left(L_{C}\right)\right)$, LY $\left(h^{2}\left(L_{S}\right)>h^{2}\left(L Y_{E}\right)\right)$, and BW8 $\left(h^{2}\left(B W 8_{S}\right)>h^{2}\left(B W 8_{C}\right), h^{2}\left(B W 8_{E}\right)\right)$. In contrast, in the last situation, the increase was greater for the residual than for genetic variance, and heritability was lower in environment $\mathrm{A}$ than in $\mathrm{B}$, as for TI $\left(h^{2}\left(\mathrm{TI}_{\mathrm{SC}}>\mathrm{h}^{2}\left(\mathrm{TI}_{\mathrm{E}}\right)\right)\right.$ and LY $\left(\mathrm{h}^{2}\left(\mathrm{LY}_{\mathrm{E}}\right)>\mathrm{h}^{2}\left(\mathrm{LY}_{\mathrm{C}}\right)\right)$.

\subsubsection{Genotype by environment interactions}

Genetic correlations for traits recorded in different environments are presented in Table IV. All the estimated genetic correlations for traits recorded in different environments were fairly high, ranging from 0.74 to 0.99 ; the more significantly the genetic correlation deviated from unity, the greater the $\mathrm{G} \times \mathrm{E}$ interaction.

Genetic correlation between $\mathrm{BW} 8_{\mathrm{C}}$ and $\mathrm{BW} 8_{\mathrm{E}}$ was not different from unity. In $\mathrm{C}$ and $\mathrm{E}$ environments, rearing conditions were changed at $6 \mathrm{wk}$ of age. In the $\mathrm{C}$ environment, growth was delayed, so that 8-wk-old animals in $\mathrm{C}$ were physiologically close to those in E which had slower growth. Similarly, no $\mathrm{G} \times \mathrm{E}$ interaction was found between $\mathrm{C}$ or $\mathrm{E}$ environments for BWS. In the latter case, the lack of $\mathrm{G} \times \mathrm{E}$ interaction was probably due to the difference in 
slaughter age between $\mathrm{E}$ and $\mathrm{C}$, suggesting that $\mathrm{C}$ animals at 10 wk have the same physiological age as $\mathrm{E}$ animals at 12 wk. On the contrary, the E environment was different from the other two for L, K, and TI. This result confirmed the value of fitting the growth curve rather than considering body weight because the former minimizes background noise and provides a better synthesis of the data collected.

For carcass traits, genetic correlations between traits measured in the different environments ranged between 0.84 and 0.95 , and most of these correlations were significantly different from unity. Our results thus showed that $\mathrm{G} \times \mathrm{E}$ interactions were present on nearly all recorded traits, but were of minor importance for carcass traits compared to body weight and growth curve parameters, in agreement with a previous study in which moderate to low $\mathrm{G} \times \mathrm{E}$ interactions were detected on body weight, BRY and AFY in chickens reared on the floor or in cages [34]. Furthermore, in the E environment, the period of access to open air coincided with the spring, i.e. favourable conditions. It can therefore be asked whether the $\mathrm{G} \times \mathrm{E}$ interaction would have been greater in less favourable conditions.

As shown in Table IV, the differences between the $\mathrm{S}$ and $\mathrm{E}$ environments led to significant $\mathrm{G} \times \mathrm{E}$ interactions for growth curve parameters, body weight and breast yield, and these $\mathrm{G} \times \mathrm{E}$ interactions should be taken into account by breeders. Correlations were particularly low for the K and TI parameters measured in both the $\mathrm{S}$ and $\mathrm{E}$ environments. In contrast, abdominal fatness and leg yield were less affected by the $\mathrm{G} \times \mathrm{E}$ interaction, meaning that selection on decreased fatness in the $\mathrm{S}$ environment should produce the expected improvement in fatness in the E environment.

\subsubsection{Selection of feed conversion in the presence of $G \times E$ interaction}

Direct improvement in FCR is possible and should be achieved with either $\mathrm{FCR}_{\mathrm{t}}$ or RES, in view of their heritability values $(0.31 \pm 0.03$ and $0.49 \pm 0.04$, respectively). According to these estimates, decreasing and thus improving $\mathrm{FCR}_{\mathrm{t}}$ should mainly result in modifying the growth curve, with a similar body weight at slaughter. Improving RES should decrease food consumption partly because birds will be lighter at 8 weeks. In spite of the compensatory growth, birds will remain lighter at slaughter, even in $\mathrm{S}$ and $\mathrm{E}$, which is not possible in label chickens, since the slaughter age cannot be modified. Moreover, direct selection on $\mathrm{FCR}_{\mathrm{t}}$ or RES involves rearing animals in cages, which is quite different from the production environment. In our case, feed consumption was on the floor, but since food spillage was fairly significant in some 
Table V. Expected response to indirect selection of $\mathrm{FCR}_{\mathrm{t}}$ or RES, using growth curve parameters or body composition as selection criteria. Responses are expressed as a percentage of expected response to direct selection.

\begin{tabular}{|c|c|c|c|c|c|c|}
\hline \multirow{2}{*}{ Trait $^{1}$} & \multicolumn{6}{|c|}{ Selection environment } \\
\hline & $\mathrm{C}^{2}$ & $S^{2}$ & $E^{2}$ & $\mathrm{C}^{2}$ & $\mathrm{~S}^{2}$ & $\mathrm{E}^{2}$ \\
\hline & \multicolumn{3}{|c|}{ Response on $\mathrm{FCR}_{\mathrm{t}}$} & \multicolumn{3}{|c|}{ Response on RES } \\
\hline $\mathrm{L}^{3}$ & \multicolumn{2}{|c|}{41.6} & 49.9 & \multicolumn{2}{|c|}{50.7} & 30.6 \\
\hline $\mathrm{K}^{3}$ & \multicolumn{2}{|c|}{44.8} & 64.7 & \multicolumn{2}{|c|}{37.1} & 48.8 \\
\hline $\mathrm{TI}^{3}$ & \multicolumn{2}{|c|}{38.4} & 69.1 & \multicolumn{2}{|c|}{20.3} & 52.1 \\
\hline BRY & 0.0 & 14.9 & 62.6 & 35.4 & 36.8 & 18.8 \\
\hline LY & 57.1 & 79.3 & 52.9 & 21.9 & 45.4 & 15.6 \\
\hline AFY & 62.2 & 35.5 & 10.8 & 51.1 & 55.3 & 11.9 \\
\hline
\end{tabular}

${ }^{1} \mathrm{BRY}, \mathrm{LY}$, and AFY = breast yield, leg yield, and abdominal fat yield, respectively; L, K, and TI = initial specific growth rate, maturation rate, and age at inflection, respectively. BW8, BWS $=$ body weight at $8 \mathrm{wk}$ and body weight at slaughter, respectively. FCRt, RES $=$ feed conversion ratio and residual food consumption between $8 \mathrm{wk}$ and $10 \mathrm{wk}$, in individual cages, respectively.

${ }^{2}$ Environment in which trait was recorded, i.e. selection (S), cage (C) or extensive (E).

${ }^{3}$ For L, K, and TI, data in selection (S) and cage (C) environments are cumulated.

pens, measurement was not precise. Finally, sire ranks changed by one third between $\mathrm{S}$ and $\mathrm{C}$.

N'Dri et al. [21] suggested using fatness and growth curve parameters as criteria for indirect selection on FCR in C, with greater efficiency of selection on fatness. To be consistent with the practical constraints of "Label Rouge" production, indirect selection for feed conversion must be undertaken either in $\mathrm{S}$ or $\mathrm{E}$ environments. Furthermore, regulation imposes a minimum age at slaughter of 81 days, and selection for increased final body weight is not possible. Therefore, indirect selection for FCR should not affect slaughter age nor modify final body weight. It discards BW of WG from the list of possible selection criteria, since both are correlated with body weight at slaughter. In the $\mathrm{S}$ environment indirect selection led to a wider expected response when growth curve parameters were used as selection criteria (Tab. V). Similarly, indirect selection in the $\mathrm{E}$ environment should be undertaken using growth curve parameters or BRY as selection criteria (Tab. V). The most interesting criterion was therefore not AFY, as was concluded from the results in the $\mathrm{C}$ environment, but growth curve parameters or leg yield. However, if a carcass trait were to be chosen as selection criterion, the effective response would be decreased by as much as $30 \%$, since selection should be performed on collaterals. 
It should be noted that indirect selection of FCR in the E environment using the TI parameter (inflection point of the growth curve) would provide the best response and would not greatly affect BWS or fatness, since these traits exhibited very low genetic correlations ( -0.15 and 0.19 for TI and K with BWS, respectively, 0.22 and -0.22 for TI and $\mathrm{K}$ with AFY, respectively).

This study shows the importance of taking $\mathrm{G} \times \mathrm{E}$ interactions into account in selection schemes, especially for a type of production that uses free-range conditions and expects high quality whole carcass products, since in this type of production, selection and production environments can be very different. Not heeding $\mathrm{G} \times \mathrm{E}$ interactions would greatly limit the impact of indirect selection for feed efficiency, and could even result in the choice of the wrong selection criteria. Furthermore, growth traits exhibited $\mathrm{G} \times \mathrm{E}$ interactions between the selection and the production environments, which could suggest that data collected in the E environment should be included in the estimation of breeding values of selection candidates.

\section{ACKNOWLEDGEMENTS}

This study was supported by SASSO (Sélection de la Sarthe et du SudOuest, Contract B04677).

\section{REFERENCES}

[1] Barbato G.F., Genetic architecture of growth curve parameters in chickens, Theor. Appl. Genet. 83 (1991) 24-32.

[2] Beaumont C., Guillaumin S., Geraert P.A., Mignon-Grasteau S., Leclercq B., Genetic parameters of body weight of broiler chickens measured at $22{ }^{\circ} \mathrm{C}$ or $32{ }^{\circ} \mathrm{C}$, Br. Poult. Sci. 39 (1998) 488-491.

[3] Bordas A., Mérat P., Correlated response in a selection experiment on residual feed intake of adult Rhode Island Red cocks and hens, Ann. Agric. Fenn. 23 (1984) 233-237.

[4] Bordas A., Tixier-Boichard M., Mérat P., Direct and correlated response to divergent selection for residual food intake in Rhode Island Red laying hens, Br. Poult. Sci. 33 (1992) 741-754.

[5] Box G.E.P., Cox D.R., An analysis of transformations, J. Res. Stat. Soc. 26 (1994) 211-243.

[6] Cahaner A., Nitzan Z., Evaluation of simultaneous selection for live body weight and against abdominal fat in broilers, Poult. Sci. 64 (1985) 1257-1263.

[7] Chambers J.R., Quantitative genetics and selection, in: Crawford R.D. (Ed.), Poultry Breeding and Genetics, Elsevier, Amsterdam, 1990, pp. 599-643. 
[8] Goliomytis M., Panopoulou E., Rogdakis E., Growth curves for body weight and major component parts, feed consumption, and mortality of male chickens raised to maturity, Poult. Sci. 82 (2003) 1061-1068.

[9] Grossman M., Bohren B.B., Anderson V.L., Logistic growth curve of chickens: a comparison of techniques to estimate parameters, J. Hered. 76 (1985) 397-399.

[10] Guill R.A., Washburn K.W., Genetic changes in efficiency of feed utilisation of chicks maintaining body weight constant, Poult. Sci. 53 (1974) 1146-1154.

[11] Horst P., Effects of genotype $\times$ environment interactions on efficiency of improvement of egg production, in: Proceedings of the 18th Poultry Science Symposium and of the 25th British Poultry Breeders Round Table, 1985, Edinburgh, UK, pp. 147-156.

[12] Jego Y., Besbes B., Donal J.L., Analyse de la variabilité génétique et de la réponse à la sélection dans deux lignées commerciales de poulets de chair, in: Proceedings of the 1st Journées de la Recherche Avicole, 1995, Angers, France, pp. $125-127$.

[13] Laird A.K., Tyler S.A., Barton A.D., Dynamics of normal growth, Growth 29 (1965) 233-248.

[14] Le Bihan-Duval E., Mignon-Grasteau S., Millet N., Beaumont C., Genetic analysis of a selection experiment on increased body weight and breast muscle weight as well as on limited abdominal fat weight, Poult. Sci. 39 (1998) 346-353.

[15] Le Bihan-Duval E., Millet N., Rémignon H., Broiler meat quality: effect of selection for increased carcass quality and estimates of genetic parameters, Poult. Sci. 78 (1999) 822-826.

[16] Leclercq B., Guy G., Rudeaux F., Growth characteristics and lipid distribution in two lines of chickens selected for low or high abdominal fat, Genet. Sel. Evol. 21 (1989) 69-80.

[17] Lewis P.D., Perry G.C., Farmer L.J., Patterson R.L.S., Responses of two genotypes of chicken to the diets and stocking densities typical of UK and "Label Rouge" production systems: I. Performance, behaviour and carcass composition, Meat Sci. 45 (1997) 501-516.

[18] Mignon-Grasteau S., Beaumont C., Genetic parameters of growth curve in chickens, in: Proceedings of the 7th World Congress of Genetics Applied to Livestock, 2002, Montpellier, France, communication 11-03.

[19] Mignon-Grasteau S., Beaumont C., Le Bihan-Duval E., Poivey J.P., de Rochambeau H., Genetic parameters of growth curve parameters in male and female chickens, Br. Poult. Sci. 40 (1999) 44-51.

[20] N'Dri A.L., Sellier N., Beaumont C., Tixier-Boichard M., Mignon-Grasteau S., Genotype by environment interaction on growth curve in chicken, in Proceedings of the 22th World Poultry Congress, 2004, Istambul, Turkey, 155 p.

[21] N'Dri A.L., Mignon-Grasteau S., Sellier S., Tixier-Boichard M., Beaumont C., Genetic relationships between feed conversion ratio, growth curve and body composition in slow growing chickens, Br. Poult. Sci. 47 (2006) 273-280.

[22] Neumaier A., Groeneveld E., Restricted maximum likelihood of covariances in sparse linear models, Genet. Sel. Evol. 30 (1998) 13-26.

[23] Pym R.A. E., Nutritional genetics, in: Crawford R.D. (Ed.), Poultry Breeding and Genetics, Elsevier, Amsterdam, 1990, pp. 847-876. 
[24] Pym R.A.E., Nicholls P.J., Selection for food conversion in broilers: direct and indirect responses to selection for body weight gain, food consumption and food conversion ratio, Br. Poult. Sci. 20 (1979) 73-86.

[25] Quentin M., Bouvarel I., Berri C., Le Bihan-Duval E., Baeza E., Jego Y., Picard M., Growth, carcass composition and meat quality responses to dietary concentrations in fast-, medium- and slow-growing commercial broilers, Anim. Res. 52 (2003) 65-77.

[26] Ricard R.H., Indice de consommation et état d'engraissement de poulets appartenant à des souches sélectionnées sur la forme de la courbe de croissance, in: Proceedings of the 16th World Poultry Congress, 1978, Rio de Janeiro, Brasil, pp. 1786-1793.

[27] SAS ${ }^{\circledR}$ Institute, SAS ${ }^{\circledR} /$ STAT User's guide. Version 8, SAS ${ }^{\circledR}$ Inst., Inc., Cary, NC, 1999.

[28] Sauveur B., Les critères et facteurs de la qualité des poulets Label Rouges, INRA Prod. Anim. 10 (1997) 219-226.

[29] Tixier-Boichard M., Boichard D., Groeneveld E., Bordas A., Restricted maximum likelihood estimates of genetic parameters of adult male and female Rhode Island Red chickens divergently selected for residual feed consumption, Poult. Sci. 74 (1995) 1245-1252.

[30] van Der Horst F., Réduction du taux de déclassement pour ampoules au bréchet chez le poulet label par limitation de la croissance au démarrage, Sci. Tech. Avic. 13 (1995) 30-37.

[31] Vereijken A.L.J., Genetics of body conformation and breast meat yield in broilers, in: Proceedings of the 19th World Poultry Congress, 1992, Amsterdam, The Netherlands, pp. 98-100.

[32] Wang L., McMillan I., Chambers J.R., Genetic correlations among growth, feed, and carcass traits of broilers sire and dam populations, Poult. Sci. 70 (1991) 719-725.

[33] Weeks C.A., Nicol C.J., Sherwin C.M., Kerstin S.C., Comparison of the behaviour of broiler chickens in indoor and free-range environments, Anim. Welfare 3 (1994) 179-192.

[34] Zerehdaran S., Vereijken A.L.J., van Arendonk J.A.M., van der Waaij E.H., Effect of age and housing system on genetic parameters for broiler carcass traits, Poult. Sci. 84 (2005) 833-838. 